\title{
Fontes proteicas em suplementos para novilhos no período de transição seca-águas: características nutricionais
}

[Protein sources in supplements for bulls in the dry-rainy transition season: nutritional characteristics]

\author{
T.S. Acedo ${ }^{1}$, M.F. Paulino ${ }^{2,3}$, E. Detmann ${ }^{2,3}$, S.C. Valadares Filho ${ }^{2,3}$, M.F.L. Sales ${ }^{1}$, M.O. Porto ${ }^{1}$ \\ ${ }^{1}$ Aluno de pós-graduação - UFV - Viçosa, MG - Bolsista do CNPq \\ ${ }^{2}$ Departamento de Zootecnia - UFV \\ 36570-000 - Viçosa, MG \\ ${ }^{3}$ Pesquisador de produtividade - $\mathrm{CNPq}$
}

\begin{abstract}
RESUMO
Avaliaram-se fontes proteicas em suplementos para novilhos em pastagens de Brachiaria decumbens Stapf., durante a transição seca-águas, sobre as características nutricionais. Utilizaram-se quatro animais Holandês x Zebu, não castrados, com média de peso de $300 \mathrm{~kg}$, fistulados no esôfago, rúmen e abomaso, distribuídos em delineamento em quadrado latino 4x4. Avaliaram-se suplementos isoproteicos, balanceados para $38 \%$ de proteína bruta $(\mathrm{PB})$, sendo um tratamento controle mistura mineral (MM); e três suplementos à base de grãos de milho moído + ureia (MU); grãos de milho moído + farelo de soja (MFS) e farelo de algodão $38 \%$ PB (FA), fornecidos na quantidade de $0,17 \%$ do peso vivo (PV). O consumo de fibra em detergente neutro pelos animais do tratamento $\mathrm{MU}$, de $12,1 \mathrm{~g} / \mathrm{kg} \mathrm{PV}$, foi maior em $19,9 \%$ do que o observado para os dos tratamentos MM e MFS, 10,2g/kg PV, e semelhante ao observado para os do tratamento FA, 11,0g/kg PV. Foram observados valores mais altos de digestibilidade aparente total da matéria seca (MS) para os tratamentos MU e MFS em relação aos demais. Os valores de pH ruminal, produção de nitrogênio microbiano e eficiência de síntese microbiana não foram influenciados pelos tratamentos. A suplementação com MU proporciona maior consumo e digestibilidade aparente total da MS em relação ao tratamento MM.
\end{abstract}

Palavras-chave: amônia ruminal, consumo, digestibilidade, suplementação, ureia

\begin{abstract}
This study was conducted to evaluate protein sources in supplements for bulls grazing Brachiaria decumbens Stap., in the dry-rainy transition season, regarding nutritional characteristics. Four Holstein $x$ Zebu bulls (300kg of body weight - BW) fitted with esophageal, ruminal, and abomasal cannulas, allotted in a latin square experimental design $4 x 4$. The treatments were protein supplements with $38 \%$ of crude protein $(C P)$ based on grounded corn grain + urea $(G C U)$; grounded corn grain + soybean meal $(G C S B)$; and cotton seed meal (38\% CP) (CSM), supplied at a level of $0.17 \% \mathrm{BW}$, and a mineral mix control treatment $(M M)$. The animals fed diets of GCU treatment showed neutral detergent fiber (NDF) intake of $12.1 \mathrm{~g} / \mathrm{kg}$ of $B W, 19.9 \%$ greater than the observed on animals fed diets of MM and GCSB, 10.2 $\mathrm{g} / \mathrm{kg}$ of $B W$, and similar to the NDF intake found for animals fed CSM treatment, $11.0 \mathrm{~g} / \mathrm{kg}$ of BW. The dry matter (DM) total apparent digestibility (TAD) was higher for GCU and GCSB treatments. The ruminal pH, microbial nitrogen production (MNP), and microbial synthesis efficiency (MSE) were not influenced by the treatments. The supplementation with corn and urea provides greater DM intake and digestibility when compared to the mineral mix.
\end{abstract}

Keywords: digestibility, intake, ruminal ammonia, supplementation, urea

Recebido em 10 de março de 2010

Aceito em 1 de junho de 2011

E-mail: tiagotsa@hotmail.com

Apoio: FAPEMIG e CNPq 


\section{INTRODUÇÃO}

Durante as épocas de transição seca-águas e águas, quando as gramíneas tropicais apresentam valores nutricionais mais elevados, animais em pastejo, apenas com suplementação mineral, apresentam desempenho abaixo do desejado em sistemas de bovinocultura de ciclo curto (Detmann et al., 2001a; Figueiredo et al., 2004; Porto, 2005; Paulino et al., 2006; Acedo, 2007).

As gramíneas tropicais não são consideradas, durante as águas, deficitárias em nitrogênio e apresentam, de maneira geral, teores próximos a $10 \%$ de proteína bruta (PB). Contudo, tem-se verificado que altas proporções de compostos nitrogenados contidos na forragem, também na época das chuvas, podem estar ligados à fração fibrosa da parede celular, apresentando lenta taxa de degradação ou mesmo indisponibilidade. Paulino et al. (2002a), em compilação de dados sobre o gênero Brachiaria, encontraram cerca de $40 \%$ do nitrogênio total da forragem na forma insolúvel em detergente neutro (NIDN) e 6\% na forma insolúvel em detergente ácido (NIDA).

Segundo Minson (1990), os microrganismos ruminais requerem, no mínimo, $7 \%$ de $\mathrm{PB}$ dietética para manutenção da atividade fermentativa ruminal, entretanto Hunter (1991) apresentou como valor crítico para a síntese microbiana o teor de $10 \%$ de PB na matéria seca (MS), enfatizando que pode ocorrer comprometimento dos níveis de proteína microbiana que chegam ao intestino, caso haja deficiência de aminoácidos, de amônia e energia no ambiente ruminal.

Adicionalmente, segundo Leng (1990), em condições tropicais, o consumo de MS por bovinos é maximizado quando o nitrogênio amoniacal ruminal (NAR) alcança valores próximos a 20mg/dL. No entanto, têm sido verificadas concentrações de NAR para animais em pastejo durante a estação chuvosa, recebendo apenas mistura mineral, abaixo de $9 \mathrm{mg} / \mathrm{dL}$ (Detmann et al., 2001a; Figueiredo et al., 2004; Porto, 2005; Paulino et al., 2006), valor aquém do patamar sugerido por Leng (1990).

A suplementação durante as águas fornece nutrientes para melhor adequação do ambiente ruminal, principalmente no que se refere aos compostos nitrogenados, estimulando a atividade microbiana e acelerando a taxa de degradação ruminal da fração fibrosa, de modo que a fração indigestível deixe o rúmen o mais rápido possível, o que resulta em maximização do consumo de forragem e maior aporte de nutrientes ao intestino.

O presente estudo foi realizado com o objetivo de avaliar o efeito de fontes proteicas em suplementos múltiplos, para novilhos mestiços, durante a época de transição seca-águas, mantidos em pastagens de Brachiaria decumbens Stapf., sobre as características nutricionais.

\section{MATERIAL E MÉTODOS}

O experimento foi realizado na Central de Experimentação, Pesquisa e Extensão do Triângulo Mineiro da Universidade Federal de Viçosa, na época de transição seca-águas, entre os meses de outubro a dezembro de 2002.

Utilizaram-se quatro animais mestiços Holandês x Zebu, não castrados, com peso médio inicial de $300 \mathrm{~kg}$, fistulados no esôfago, rúmen e abomaso. Os animais foram distribuídos em delineamento em quadrado latino, com quatro tratamentos e quatro períodos experimentais de 14 dias cada, perfazendo 56 dias de avaliação. Realizaram-se pesagens dos animais no início e final de cada período. Os sete primeiros dias de cada período foram destinados à adaptação dos animais ao suplemento.

A área experimental destinada aos animais foi composta de quatro piquetes de Brachiaria decumbens Stapf. de 0,4ha cada. Foram realizados rodízios dos animais entre os piquetes experimentais a cada sete dias, visando eliminar possíveis diferenças em relação à disponibilidade de forragem entre os piquetes.

Avaliaram-se os suplementos isoproteicos, apresentados na Tab. 1, balanceados para conter $38 \%$ de PB com base na matéria natural, sendo um tratamento controle - constituído apenas de mistura mineral $(\mathrm{MM})$ - e três suplementos à base de grãos de milho moído + ureia/sulfato de amônia (MU); grãos de milho moído + farelo de soja (MFS) e farelo de algodão $38 \%$ de PB (FA).

Os suplementos foram fornecidos diariamente às $10 \mathrm{~h}$, na quantidade correspondente a aproximadamente $0,17 \%$ do PV. Todos os animais receberam $60 \mathrm{~g} / \mathrm{dia}$ de mistura mineral completa. 
Tabela 1. Composição percentual dos suplementos, com base na matéria natural

\begin{tabular}{lcccc}
\multicolumn{1}{c}{ Ingrediente (\%) } & MM & MU & MFS & FA \\
\hline Grãos de milho moído & 0,0 & 87,5 & 20,0 & 0,0 \\
Ureia/Sulfato de amônia (9:1) & 0,0 & 12,5 & 0,0 & 0,0 \\
Farelo de soja & 0,0 & 0,0 & 80,0 & 0,0 \\
Farelo de algodão 38\% PB & 0,0 & 0,0 & 00 & 100,0 \\
Mistura mineral & 100,0 & 0,0 & 0,0 & 0,0 \\
\hline
\end{tabular}

MM: mistura mineral (composição percentual: fosfato bicálcico: 50,0; cloreto de sódio: 47,7; sulfato de zinco: 1,4; sulfato de cobre: 0,8; sulfato de cobalto: 0,05 e iodato de potássio: 0,05); MU: suplemento à base de grãos de milho moído + ureia/sulfato de amônia; MFS: suplemento à base de grãos de milho moído + farelo de soja; FA: suplemento à base de farelo de algodão $38 \%$ de PB.

Foram realizadas coletas de pasto para avaliação da disponibilidade total de MS, no quinto dia de cada periodo experimental, conforme recomendações de McMeniman (1997). Para avaliação da composição química da forragem, também foram realizadas, no quinto dia de cada período, coletas de extrusa (McMeniman, 1997). As amostras foram processadas e submetidas a análises laboratoriais segundo recomendações de Silva e Queiroz (2002), com exceção da determinação do teor de fibra em detergente ácido indigestível (FDAi), obtido por intermédio de incubação in situ por 144 horas.

$\mathrm{Na}$ estimação da produção de MS fecal e do fluxo de MS abomasal, utilizaram-se 10 gramas de óxido crômico, acondicionadas em cartuchos de papel, fornecidas diretamente no rúmen em uma única dose às $11 \mathrm{~h}$, a partir do terceiro dia do período experimental, até o final de cada período.

Realizaram-se três coletas de fezes e de digesta abomasal, de cada animal, por período experimental, no oitavo, no $10^{\circ}$ e no $12^{\circ}$ dia do período às 8,12 e 16h, respectivamente. Após o processamento, foram confeccionadas amostras compostas de fezes e de digesta abomasal, relativas a cada animal por período, para posteriores análises laboratoriais.

No $13^{\circ}$ dia do período, foram obtidas amostras spot de urina, durante micção espontânea dos animais, aproximadamente $4 \mathrm{~h}$ após o fornecimento dos suplementos. Após as coletas, foram realizadas diluições de $10 \mathrm{~mL}$ de urina em $40 \mathrm{~mL}$ de $\mathrm{H}_{2} \mathrm{SO}_{4}(0,036 \mathrm{~N})$. As amostras diluídas foram acondicionadas em potes plásticos com tampa e congeladas a $-20^{\circ} \mathrm{C}$. Ao final do experimento, foram analisadas para determinação de ureia e creatinina, segundo método diacetil modificado e com o uso de picrato e acidificante, respectivamente, ambos kits comerciais (Labtest).

No $14^{\circ}$ dia do período experimental, realizaramse coletas de líquido ruminal, $4 \mathrm{~h}$ após o fornecimento dos suplementos, para quantificar o $\mathrm{pH}$ e a concentração de NAR. Amostras de líquido ruminal foram tomadas na região de interface líquido:sólido, filtradas por camada tripla de gaze e imediatamente avaliadas quanto ao $\mathrm{pH}$. Alíquotas de $50 \mathrm{~mL}$ foram fixadas com $1 \mathrm{~mL}$ de $\mathrm{H}_{2} \mathrm{SO}_{4}(1: 1)$ e congeladas a $-20^{\circ} \mathrm{C}$ para posterior avaliação de NAR.

$\mathrm{Na}$ estimação da produção de nitrogênio microbiano (Nmic) e eficiência de síntese microbiana (Efim), utilizaram-se, como indicadores, as bases purinas na digesta abomasal, quantificadas segundo técnica descrita por Ushida et al. (1985). Empregou-se o valor de $15,45 \%$, obtido por Ítavo et al. (2002) para a relação U-RNA:N-total.

O fluxo de MS abomasal e o consumo voluntário de MS foram estimados utilizando como indicador interno a FDAi, de acordo com os métodos descritos por Detmann et al. (2001b). O volume urinário diário foi estimado pela relação entre a excreção diária de creatinina, adotando-se o padrão de $27,76 \mathrm{mg} / \mathrm{kg} \mathrm{PV}$ (Rennó et al., 2002), e sua concentração nas amostras spot.

$\mathrm{O}$ experimento foi analisado em delineamento em quadrado latino $4 \times 4$, sendo as comparações entre médias de tratamentos realizadas pelo teste de média, adotando-se o teste DMS de Fisher e significância de $10 \%$. Todos os procedimentos estatísticos foram realizados pelo SAS. 


\section{RESULTADOS E DISCUSSÃO}

Durante o experimento a disponibilidade média de MS foi de $6873 \mathrm{~kg} / \mathrm{ha}$, valor próximo à média de $7445 \mathrm{~kg} / \mathrm{ha}$, obtida tendo como referência os valores encontrados por Detmann et al. (2001a), Zervoudakis et al. (2001), Acedo (2004) e Porto
(2005), de 9548, 6836, 8625 e 4770kg/ha, respectivamente, em situações semelhantes.

A composição química da Brachiaria decumbens Stapf. e dos suplementos é apresentada na Tab. 2.

Tabela 2. Composição química da extrusa de B. decumbens Stapf. e dos suplementos

\begin{tabular}{|c|c|c|c|c|c|}
\hline Item & MM & MU & MFS & FA & Extrusa \\
\hline Matéria seca (\%) & 98,70 & 88,85 & 88,54 & 89,95 & 9,18 \\
\hline Matéria orgânica ${ }^{1}$ & - & 99,06 & 94,84 & 94,79 & 86,66 \\
\hline Proteína bruta $^{1}$ & - & 41,64 & 40,69 & 39,35 & 10,41 \\
\hline Proteína degradável no rúmen ${ }^{2,3}$ & - & 92,73 & 74,12 & 70,07 & 65,28 \\
\hline Nitrogênio insolúvel em detergente neutro ${ }^{4}$ & - & 8,13 & 3,66 & 10,44 & 48,15 \\
\hline Nitrogênio insolúvel em detergente ácido ${ }^{4}$ & - & 4,59 & 2,12 & 5,38 & 5,98 \\
\hline Extrato etéreo $^{1}$ & - & 3,56 & 2,18 & 1,87 & 1,73 \\
\hline Cinzas $^{1}$ & - & 0,94 & 5,16 & 5,21 & 13,34 \\
\hline Fibra em detergente neutro ${ }^{1}$ & - & 10,16 & 15,26 & 35,71 & 56,11 \\
\hline $\begin{array}{l}\text { Fibra em detergente neutro corrigida para } \\
\text { cinzas e proteína }{ }^{1}\end{array}$ & - & 6,98 & 13,05 & 31,46 & 50,43 \\
\hline Carboidratos não fibrosos ${ }^{1}$ & - & 43,70 & 36,72 & 17,86 & 18,41 \\
\hline $\begin{array}{l}\text { Carboidratos não fibrosos corrigidos para } \\
\text { cinzas e proteína }{ }^{1}\end{array}$ & - & 46,90 & 38,90 & 22,10 & 24,09 \\
\hline Fibra em detergente ácido ${ }^{1}$ & - & 3,82 & 9,30 & 28,18 & 38,79 \\
\hline Fibra em detergente ácido indigestível ${ }^{1}$ & - & 0,49 & 0,34 & 15,50 & 15,13 \\
\hline Lignina $^{1}$ & - & 1,34 & 1,43 & 4,14 & 8,17 \\
\hline $\mathrm{NDT}^{1,5}$ & - & 75,01 & 80,71 & 68,99 & 47,07 \\
\hline
\end{tabular}

MS - Matéria seca; MO - Matéria orgânica; PB - Proteína bruta; PDR - Proteína degradável no rúmen, NIDN Nitrogênio insolúvel em detergente neutro; NIDA - Nitrogênio insolúvel em detergente ácido; EE - Extrato etéreo; FDN - Fibra em detergente neutro; FDNcp - Fibra em detergente neutro corrigida para cinzas e proteína; CNF Carboidratos não fibrosos; CNFcp - Carboidratos não fibrosos corrigido para cinzas e proteína; FDA - Fibra em detergente ácido; FDAi - Fibra em detergente ácido indigestível; NDT - Nutrientes digestíveis totais; ${ }^{1} \%$ MS; ${ }^{2} / \mathrm{PDR}$ $=\mathrm{A}+\mathrm{B}(\mathrm{Kd} / \mathrm{Kd}+\mathrm{Kp})\left(\right.$ Nutrient Requirements of Dairy Cattle, 2001), \%PB total; ${ }^{3} /$ Valores de A (\%), B (\%) e Kd $(\% / h)$ utilizados: $25,40,72,13$ e 3,36 para o grão de milho moído; $18,26,85,51$ e 9,80 para o farelo de soja e 22,70, 68,09 e 11,43 para o farelo de algodão 38\% e 60,65, 16,87 e 9,98 para a extrusa de $B$. decumbens (Valadares Filho et al. 2006a); valor de $\mathrm{Kp}-5,0 \% / \mathrm{h} ;{ }^{4} / \%$ Nitrogênio total; ${ }^{5} /$ Estimado segundo Nutrient Requirements of Dairy Cattle (2001). MM: mistura mineral (controle); MU: suplemento à base de grãos de milho moído + ureia/sulfato de amônia; MFS: suplemento à base de grãos de milho moído + farelo de soja; FA: suplemento à base de farelo de algodão $38 \%$ de PB.

Foram observados teores de PB da pastagem de Brachiaria decumbens Stapf. de 8,5; 8,7; 9,8 e $14,6 \%$ na MS, para o primeiro, segundo, terceiro e quarto períodos experimentais, respectivamente. $\mathrm{O}$ teor médio de $\mathrm{PB}$ da extrusa durante o experimento foi de $10,4 \%$ na MS, valor próximo aos encontrados por Paulino et al. (2002b), Villela et al. (2003), Zervoudakis (2003) e Acedo (2004), respectivamente, de 11,7, $9,8,10,8$ e $9,4 \%$ de PB na MS para a Brachiaria decumbens, durante o período das águas.
As estimativas de consumo médio diário de nutrientes, expressas em kg/dia e g/kg de PV, em função dos suplementos, são apresentadas na Tab. 3. Os consumos de matéria seca de pasto (MSP) e matéria orgânica de pasto (MOP) não diferiram $(\mathrm{P}>0,10)$ segundo os suplementos. Entre os animais do suplemento MU, o consumo de MS foi maior $(\mathrm{P}<0,10)$ que o observado para os do grupo-controle. A média de consumo de todos os animais suplementados foi de $21,0 \mathrm{~g}$ de $\mathrm{MS} / \mathrm{kg}$ de PV, contra os $18,3 \mathrm{~g}$ de $\mathrm{MS} / \mathrm{kg}$ de PV, verificada entre os animais do tratamento controle. 
Fontes proteicas em suplementos...

Tabela 3. Médias e coeficientes de variação do consumo de nutrientes, segundo os suplementos

\begin{tabular}{lccccc}
\hline \multicolumn{1}{c}{ Item } & MM & MU & MFS & FA & CV $(\%)$ \\
\hline & \multicolumn{4}{c}{$\mathrm{kg} / \mathrm{dia}$} \\
Matéria seca total & $5,296 \mathrm{~b}$ & $6,611 \mathrm{a}$ & $5,683 \mathrm{ab}$ & $5,885 \mathrm{ab}$ & 14,2 \\
Matéria seca de pasto & $5,296 \mathrm{a}$ & $6,166 \mathrm{a}$ & $5,240 \mathrm{a}$ & $5,435 \mathrm{a}$ & 15,1 \\
Matéria orgânica & $4,595 \mathrm{~b}$ & $5,785 \mathrm{a}$ & $4,957 \mathrm{ab}$ & $5,117 \mathrm{ab}$ & 14,0 \\
Matéria orgânica de pasto & $4,595 \mathrm{a}$ & $5,345 \mathrm{a}$ & $4,537 \mathrm{a}$ & $4,690 \mathrm{a}$ & 15,0 \\
Proteína bruta & $0,565 \mathrm{~b}$ & $0,787 \mathrm{a}$ & $0,772 \mathrm{a}$ & $0,762 \mathrm{a}$ & 18,2 \\
Extrato etéreo & $0,092 \mathrm{~b}$ & $0,122 \mathrm{a}$ & $0,097 \mathrm{~b}$ & $0,100 \mathrm{~b}$ & 14,2 \\
Fibra em detergente neutro & $2,972 \mathrm{~b}$ & $3,565 \mathrm{a}$ & $2,937 \mathrm{~b}$ & $3,160 \mathrm{ab}$ & 13,0 \\
Carboidratos não fibrosos & $0,967 \mathrm{~b}$ & $1,420 \mathrm{a}$ & $1,150 \mathrm{~b}$ & $1,097 \mathrm{~b}$ & 14,8 \\
Nutrientes digestíveis totais & $2,962 \mathrm{~b}$ & $3,700 \mathrm{a}$ & $3,142 \mathrm{ab}$ & $3,020 \mathrm{ab}$ & 19,4 \\
& & $\mathrm{~g} / \mathrm{kg}$ PV & & \\
Matéria seca & $18,3 \mathrm{~b}$ & $22,8 \mathrm{a}$ & $19,7 \mathrm{ab}$ & $20,4 \mathrm{ab}$ & 11,5 \\
Matéria orgânica & $15,8 \mathrm{~b}$ & $20,0 \mathrm{a}$ & $17,2 \mathrm{~b}$ & $17,8 \mathrm{ab}$ & 11,4 \\
Matéria seca de pasto & $18,3 \mathrm{a}$ & $21,2 \mathrm{a}$ & $18,0 \mathrm{a}$ & $18,7 \mathrm{a}$ & 12,6 \\
Matéria orgânica de pasto & $15,8 \mathrm{a}$ & $18,3 \mathrm{a}$ & $15,6 \mathrm{a}$ & $16,2 \mathrm{a}$ & 12,7 \\
Fibra em detergente neutro & $10,2 \mathrm{~b}$ & $12,1 \mathrm{a}$ & $10,2 \mathrm{~b}$ & $11,0 \mathrm{ab}$ & 12,5 \\
\hline
\end{tabular}

Médias na mesma linha, seguidas por letras distintas, diferem entre si pelo teste DMS de Fisher $(\mathrm{P}<0,10)$. Matéria seca total (MST); Matéria seca de pasto (MSP); Matéria orgânica (MO); Matéria orgânica de pasto (MOP); Proteína bruta (PB); Extrato etéreo (EE); Fibra em detergente neutro (FDN); Carboidratos não fibrosos (CNF); Nutrientes digestíveis totais (NDT). MM: mistura mineral (controle); MU: suplemento à base de grãos de milho moído + ureia/sulfato de amônia; MFS: suplemento à base de grãos de milho moído + farelo de soja; FA: suplemento à base de farelo de algodão $38 \%$ de PB.

Valor próximo de consumo de MS para animais suplementados foi encontrado por Porto (2005), $21,3 \mathrm{~g}$ de $\mathrm{MS} / \mathrm{kg}$ de PV, ao avaliar diferentes fontes de proteína em suplementos para bovinos Nelore, em fase de recria, no período das águas. Villela (2004), em situação semelhante à do presente estudo, encontrou consumo médio de MS de 22,3g de MS/kg de PV para animais suplementados.

O consumo de MST observado entre os animais do tratamento MU foi mais elevado $(\mathrm{P}<0,10)$ em $24,8 \%$ que o observado para os do grupocontrole. O maior consumo de MST observado em MU, provavelmente, foi resultado de melhor adequação do ambiente ruminal. O elevado teor de amido neste suplemento - 54,9\% na MS contra 18,2 e 5,5\% na MS nos suplementos MFS e FA, respectivamente - e a presença de ureia na sua formulação são fatores que podem ter proporcionado sincronismo apropriado na disponibilidade de nitrogênio e energia aos microrganismos ruminais, o que se refletiu em maior consumo.

Os consumos de matéria orgânica (MO) e de nutrientes digestíveis totais (NDT), expressos em $\mathrm{kg} /$ dia, seguiram o mesmo comportamento observado para MST.

O consumo de FDN pelos animais que receberam o suplemento $\mathrm{MU}, 12,1 \mathrm{~g} / \mathrm{kg} \mathrm{PV}$, foi mais alto $(\mathrm{P}<0,10)$ em $19,9 \%$ que o observado para os animais dos tratamentos MM e MFS, $10,2 \mathrm{~g} / \mathrm{kg} \mathrm{PV}$, e semelhante ao verificado para os do tratamento FA, 11,0g/kg PV.

Os animais que receberam o suplemento $\mathrm{MU}$ apresentaram consumo de carboidratos não fibrosos $(\mathrm{CNF}) 32,6 \%$ mais elevado $(\mathrm{P}<0,10) \mathrm{em}$ relação à média do consumo observado para os que receberam os demais tratamentos. Este fato é atribuído à maior participação de CNF na formulação deste suplemento.

Os valores médios estimados para a digestibilidade aparente total (DAT) da MS, MO, PB, EE FDN, CNF e níveis de NDT na dieta, em função dos suplementos, são apresentados na Tab.4. Foram observados maiores valores de DAT da MS $(\mathrm{P}<0,10)$ para os tratamentos MU e MFS em relação aos demais, sendo estes 8,0 e $6,2 \%$ mais altos que o tratamento MM, respectivamente. 
Tabela 4. Médias e coeficientes de variação da digestibilidade aparente total dos nutrientes, segundo os suplementos

\begin{tabular}{lccccc}
\hline Item & MM & MU & MFS & FA & CV (\%) \\
\hline \multicolumn{5}{c}{ Digestibilidade aparente total } \\
Matéria seca & $56,96 \mathrm{~b}$ & $61,51 \mathrm{a}$ & $60,52 \mathrm{a}$ & $56,67 \mathrm{~b}$ & 4,3 \\
Matéria orgânica & $57,93 \mathrm{~b}$ & $62,34 \mathrm{a}$ & $61,66 \mathrm{ab}$ & $58,28 \mathrm{ab}$ & 4,9 \\
Proteína bruta & $44,63 \mathrm{~b}$ & $68,32 \mathrm{a}$ & $65,35 \mathrm{a}$ & $65,37 \mathrm{a}$ & 8,5 \\
Extrato etéreo & $-16,73 \mathrm{a}$ & $13,69 \mathrm{a}$ & $-14,99 \mathrm{a}$ & $0,43 \mathrm{a}$ & 650,6 \\
Fibra em detergente neutro & $62,84 \mathrm{a}$ & $60,93 \mathrm{a}$ & $59,41 \mathrm{a}$ & $54,41 \mathrm{~b}$ & 5,6 \\
Carboidratos não fibrosos & $55,34 \mathrm{~b}$ & $68,64 \mathrm{ab}$ & $70,28 \mathrm{a}$ & $66,37 \mathrm{ab}$ & 15,5 \\
Nutrientes digestíveis totais & $49,80 \mathrm{~b}$ & $56,83 \mathrm{a}$ & $53,56 \mathrm{ab}$ & $50,88 \mathrm{~b}$ & 5,4 \\
\hline
\end{tabular}

Médias na mesma linha, seguidas por letras distintas, diferem entre si pelo teste DMS de Fisher $(\mathrm{P}<0,10)$. MM: mistura mineral (controle); MU: suplemento à base de grãos de milho moído + ureia/sulfato de amônia; MFS: suplemento à base de grãos de milho moído + farelo de soja; FA: suplemento à base de farelo de algodão $38 \%$ de PB.

O valor de DAT da MS para o tratamento FA foi semelhante ao encontrado para MM, e mais baixo $(\mathrm{P}<0,10)$ que os encontrados para $\mathrm{MU}$ e MFS. O valor de DAT da FDN para o tratamento FA foi menor $(\mathrm{P}<0,10)$ que os verificados para os demais tratamentos. Estes resultados confirmam os já relatados por Villela (2004), que encontrou menor DAT da MS e FDN, valores de 59,1 e $60,2 \%$, respectivamente, para animais que receberam suplemento à base de FA $(370 \mathrm{~g} / \mathrm{dia})$, durante o período das águas, em comparação aos demais suplementos utilizados, cujos valores foram de 61,6 e 63,3\% para MS e FDN, respectivamente.

Os valores mais baixos da DAT da MS e FDN observados no tratamento FA podem estar relacionados à característica de lenta metabolização do FA e ao reduzido teor de amido no suplemento, 5,5\% na MS, podendo ter ocorrido déficit de nitrogênio e de compostos carbônicos para o início da fase de colonização da fibra pelos microrganismos ruminais.

Apesar de não ter sido verificado efeito negativo sobre a DAT da FDN para o tratamento MFS, a baixa quantidade de amido presente neste suplemento - $18,2 \%$ na MS - pode ter restringido o crescimento microbiano, devido à reduzida disponibilidade de carboidratos prontamente fermentáveis, fonte principal de energia aos microrganismos, o que teria influenciado negativamente a ingestão de FDN, pois os animais que receberam este suplemento apresentaram consumo de FDN mais baixo
$(\mathrm{P}<0,10)$ que o observado nos do tratamento MU.

Verificou-se maior valor de DAT da MO $(\mathrm{P}<0,10)$ para o tratamento $\mathrm{MU}$ em relação ao tratamento MM, sendo, no entanto, semelhante aos valores observados para os tratamentos MFS e FA. Foram observados mais altos valores de DAT da PB $(\mathrm{P}<0,10)$ para os animais suplementados, em média $66,4 \%$, em relação aos que receberam apenas MM. Estes resultados assemelham-se aos observados por Detmann et al. (2005) e Valadares et al. (1997), que relataram elevação da DAT da PB de forma linear com o aumento do teor de PB no suplemento.

$\mathrm{Na}$ Tab.5, são apresentados os valores de digestibilidade aparente ruminal (DAR) e intestinal (DAI) da MS, MO, PB, EE FDN e CNF em função dos diferentes suplementos. Não foram encontradas diferenças $(\mathrm{P}>0,10)$ para os valores de DAR dos nutrientes entre os tratamentos, com exceção dos observados para MO.

Os estímulos sobre a degradação ruminal da FDN promovidos pelo tratamento $\mathrm{MU}$, que teoricamente propicia melhor adequação do ambiente ruminal por gerar maiores concentrações de NAR e maior disponibilidade de CNF, não foram visualizados devido ao aumento no consumo de FDN (Tab. 4), o que, automaticamente, reduziu a digestibilidade. 
Tabela 5. Médias e coeficientes de variação da digestibilidade aparente ruminal e intestinal dos nutrientes, segundo os suplementos

\begin{tabular}{|c|c|c|c|c|c|}
\hline Item & MM & MU & MFS & FA & $\mathrm{CV}(\%)$ \\
\hline \multicolumn{6}{|c|}{ Digestibilidade aparente ruminal } \\
\hline Matéria seca $^{1}$ & $65,65 \mathrm{a}$ & $65,55 \mathrm{a}$ & $56,18 \mathrm{a}$ & $59,97 \mathrm{a}$ & 12,9 \\
\hline Matéria orgânica $^{1}$ & $78,82 \mathrm{a}$ & $72,89 \mathrm{ab}$ & $68,26 \mathrm{~b}$ & $73,84 \mathrm{ab}$ & 8,1 \\
\hline Proteína bruta ${ }^{2}$ & $9,24 \mathrm{a}$ & $13,91 \mathrm{a}$ & $17,40 \mathrm{a}$ & $11,91 \mathrm{a}$ & 256,7 \\
\hline Extrato etéreo $^{2}$ & $-116,60 \mathrm{a}$ & $-66,94 a$ & $-124,77 \mathrm{a}$ & $-107,79 a$ & 70,5 \\
\hline Fibra em detergente neutro ${ }^{1}$ & $91,76 \mathrm{a}$ & $91,37 \mathrm{a}$ & $92,50 \mathrm{a}$ & $96,29 a$ & 12,2 \\
\hline Carboidratos não fibrosos ${ }^{1}$ & $90,25 \mathrm{a}$ & $78,36 \mathrm{a}$ & $38,30 \mathrm{a}$ & $70,47 \mathrm{a}$ & 56,8 \\
\hline \multicolumn{6}{|c|}{ Digestibilidade aparente intestinal } \\
\hline Matéria seca ${ }^{1}$ & $34,35 \mathrm{a}$ & $34,45 \mathrm{a}$ & $43,82 \mathrm{a}$ & $40,03 \mathrm{a}$ & 20,6 \\
\hline Matéria orgânica $^{1}$ & $21,18 b$ & $27,11 \mathrm{ab}$ & $31,74 \mathrm{a}$ & $26,16 \mathrm{ab}$ & 22,5 \\
\hline Proteína bruta ${ }^{2}$ & $43,91 b$ & $65,13 \mathrm{a}$ & $55,48 \mathrm{ab}$ & $60,86 a b$ & 23,5 \\
\hline Extrato etéreo $^{2}$ & $45,08 \mathrm{a}$ & $43,35 \mathrm{a}$ & $46,46 \mathrm{a}$ & $48,69 \mathrm{a}$ & 45,1 \\
\hline Fibra em detergente neutro ${ }^{1}$ & $8,24 \mathrm{a}$ & $8,63 \mathrm{a}$ & $7,50 \mathrm{a}$ & $3,71 \mathrm{a}$ & 161,7 \\
\hline Carboidratos não fibrosos ${ }^{1}$ & $9,75 \mathrm{a}$ & $21,64 \mathrm{a}$ & $61,70 \mathrm{a}$ & $29,53 a$ & 128,5 \\
\hline
\end{tabular}

Médias na mesma linha, seguidas por letras distintas, diferem entre si pelo teste DMS de Fisher $(\mathrm{P}<0,10) .{ }^{1} / \%$ do total digerido; ${ }^{2} \%$ da quantidade que chegou no local. MM: mistura mineral (controle); MU: suplemento à base de grãos de milho moído + ureia/sulfato de amônia; MFS: suplemento à base de grãos de milho moído + farelo de soja; FA: suplemento à base de farelo de algodão $38 \%$ de PB.

Os valores do $\mathrm{pH}$ ruminal, nitrogênio amoniacal ruminal (NAR), excreção urinária de nitrogênio ureico (NUR), excreção de ureia na urina (UUR), produção de nitrogênio microbiano (Nmic), eficiência de síntese microbiana (Efim) e relação entre o nitrogênio de origem microbiana e o nitrogênio consumido (Nmic/NC), em função dos suplementos, são apresentados na Tab. 6.

Tabela 6. Médias e coeficientes de variação do pH ruminal, NAR (mg/dL), NUR (g/dia), UUR (mgU/kg de PV), Nmic (g/dia), Efim (g de Nmic/100 g de NDT) e Nmic/NC (\%), segundo os suplementos

\begin{tabular}{lccccc}
\hline Item & MM & MU & MFS & FA & CV (\%) \\
\hline pH & $6,34 \mathrm{a}$ & $6,19 \mathrm{a}$ & $6,43 \mathrm{a}$ & $6,22 \mathrm{a}$ & 3,2 \\
Nitrogênio amoniacal ruminal & $12,27 \mathrm{~b}$ & $18,36 \mathrm{a}$ & $16,57 \mathrm{ab}$ & $15,06 \mathrm{ab}$ & 27,9 \\
Excreção urinária de nitrogênio ureico & $22,59 \mathrm{~b}$ & $31,72 \mathrm{a}$ & $34,41 \mathrm{a}$ & $30,23 \mathrm{a}$ & 13,7 \\
Excreção de ureia na urina & $203,88 \mathrm{~b}$ & $275,33 \mathrm{a}$ & $297,81 \mathrm{a}$ & $271,86 \mathrm{a}$ & 12,8 \\
Produção de nitrogênio microbiano & $55,25 \mathrm{a}$ & $67,58 \mathrm{a}$ & $56,36 \mathrm{a}$ & $64,75 \mathrm{a}$ & 21,8 \\
Eficiência de síntese microbiana & $13,58 \mathrm{a}$ & $11,69 \mathrm{a}$ & $11,99 \mathrm{a}$ & $14,08 \mathrm{a}$ & 16,4 \\
Nitrogênio microbiano/nitrogênio consumido & $65,81 \mathrm{a}$ & $53,48 \mathrm{ab}$ & $48,48 \mathrm{~b}$ & $56,14 \mathrm{ab}$ & 16,0 \\
\hline
\end{tabular}

Médias na mesma linha, seguidas por letras distintas, diferem entre si pelo teste DMS de Fisher $(\mathrm{P}<0,10)$. MM: mistura mineral (controle); MU: suplemento à base de grãos de milho moído + ureia/sulfato de amônia; MFS: suplemento à base de grãos de milho moído + farelo de soja; FA: suplemento à base de farelo de algodão $38 \%$ de PB.

Os valores de $\mathrm{pH}$ ruminal não foram influenciados $(\mathrm{P}>0,10)$ pelos tratamentos $\mathrm{e}$ mantiveram-se acima dos valores considerados como inibitórios à atividade fibrolítica dos microrganismos ruminais $(6,0-6,1)$, não havendo, desta forma, efeitos deletérios à degradação da fração fibrosa da dieta (Mould et al., 1983).

Verificou-se maior valor de NAR $(\mathrm{P}<0,10)$ para os animais que receberam o tratamento $\mathrm{MU}$ em relação aos que receberam $\mathrm{MM}$, sendo, no entanto, semelhante aos encontrados para MFS e FA. Fato este já esperado devido à participação da ureia na formulação do suplemento MU (12,5\% ureia/sulfato de amônia 9:1; Tab. 1).

Entre os parâmetros da nutrição proteica, a concentração de NAR tem sido frequentemente empregada como referência à qualidade das condições ruminais para as atividades microbianas (Lazzarini, 2007), especialmente no 
que se refere aos microrganismos que degradam carboidratos fibrosos, os quais empregam o NAR como fonte nitrogenada para o crescimento. Níveis deficitários de NAR implicam redução no crescimento microbiano tanto por deficiência direta como por ampliação dos custos energéticos para captação destes compostos no meio (Wallace et al., 1997).

Satter e Slyter (1974) sugeriram como ótimo para maximizar o crescimento microbiano a concentração de NAR entre 5 e $8 \mathrm{mg} / \mathrm{dL}$, e, desde então, esse patamar tem sido amplamente aceito. No entanto, Leng (1990) relatou que, em condições tropicais, seriam necessários valores de 10 e 20mg/dL de NAR para a maximização da degradação ruminal da forragem e consumo voluntário, respectivamente, enquanto Lazzarini (2007), ao estudar o consumo, a digestibilidade e a dinâmica de trânsito e degradação de FDN em bovinos alimentados com forragem tropical, encontrou concentração de NAR de $15,33 \mathrm{mg} / \mathrm{dL}$ para a maximização do consumo.

Detmann et al. (2001a), Figueiredo et al. (2004), Porto (2005) e Paulino et al. (2006) verificaram valores de NAR de 6,60, 8,23, 6,86, e $8,77 \mathrm{mg} / \mathrm{dL}$, respectivamente, para animais em pastejo de Brachiaria decumbens, durante o período das águas recebendo MM, valores estes mais baixos que o observado no presente estudo de $12,27 \mathrm{mg} / \mathrm{dL}$.

Os dados apresentados por estes autores demonstram que gramíneas tropicais nas águas apresentam quantidades relativamente altas de compostos nitrogenados não proteicos em sua composição, principalmente nos períodos iniciais de rebrota. Contudo, animais em pastejo que receberam somente mistura mineral apresentaram valores de NAR abaixo dos 10mg/dL proposto por Leng (1990), necessários para maximizar a atividade fermentativa. Salienta-se, no entanto, que o valor de NAR observado para MM no presente estudo foi maior que o proposto pelo referido autor.

O valor de NAR de $18,36 \mathrm{mg} / \mathrm{dL}$ para os animais que receberam o tratamento MU (Tab. 6) é próximo ao relatado por Leng (1990) como o patamar no qual o consumo voluntário é maximizado em condições tropicais. $\mathrm{O}$ valor de $\mathrm{NAR}$, aliado ao do $\mathrm{pH}$, que se manteve acima do considerado inibitório à atividade microbiana fibrolítica, parece ter sido fator que forneceu condições ruminais bastante favoráveis, uma vez que foram registrados maiores valores para o consumo de MST (Tab. 3) e DAT da MS (Tab. 4).

Segundo Paulino et al. (2002a), frequentemente os animais respondem ao fornecimento de proteína extra durante a estação das chuvas. As gramíneas tropicais apresentam melhor qualidade nutricional durante o período das águas, em comparação à seca, mas, mesmo assim, ocorre elevado teor de NIDN e NIDA durante o período das chuvas. No presente estudo, foram observados valores de 48,1 e 6,0\% para NIDN e NIDA, respectivamente, na extrusa, durante $o$ período experimental (Tab. 2). O nitrogênio ligado à FDN, representado pelo NIDN, apresenta lenta taxa de degradação ruminal. Nesta situação, possivelmente ocorra déficit de nitrogênio aos microrganismos ruminais, sendo assim, as respostas positivas obtidas com o uso de suplementação são, provavelmente, atribuídas à maior disponibilidade de compostos nitrogenados no ambiente ruminal, conforme apresentado neste trabalho.

Não houve diferenças $(\mathrm{P}>0,10)$ sobre Nmic e Efim, segundo os suplementos, e os valores médios verificados foram de $60,99 \mathrm{~g} / \mathrm{dia}$ e $12,84 \mathrm{~g}$ de Nmic/100g de NDT (Tab. 6), respectivamente. Os valores observados de Efim foram próximos a $13 \mathrm{~g}$ PBmic/100g de NDT, proposto pelo Nutrient... (2001). No entanto, é válido salientar que tal recomendação é generalista, podendo não ser aplicável em condições tropicais. A esse respeito, Valadares Filho et al. (2006b) recomendaram, como referencial teórico, $12 \mathrm{~g}$ PBmic $/ 100 \mathrm{~g}$ de NDT para condições tropicais. Zervoudakis (2003), Villela (2004) e Moraes (2006), em condições semelhantes às do presente estudo, também não verificaram efeito sobre a Efim para animais suplementados no período das águas, relatando valores médios de $11,74,11,70$ e $11,90 \mathrm{~g}$ $\mathrm{PBmic} / 100 \mathrm{~g}$ de NDT, respectivamente. 


\section{CONCLUSÕES}

A suplementação com milho e ureia para novilhos em pastejo em quantidades próximas a $0,17 \%$ do PV, durante a época de transição secaáguas, proporciona maior consumo e digestibilidade aparente total da MS em relação à mistura mineral.

\section{REFERÊNCIAS BIBLIOGRÁFICAS}

ACEDO, T.S. Suplementos múltiplos para bovinos em terminação, durante a época da seca e em recria, nos períodos de transição seca-águas e águas. 2004. 58f. Dissertação (Mestrado em Zootecnia) - Universidade Federal de Viçosa, Viçosa-MG.

ACEDO, T.S. Suplementação múltipla para bovinos manejados a pasto em recria e terminação. 2007. 113f. Tese (Doutorado em Zootecnia) Universidade Federal de Viçosa, Viçosa-MG.

DETMANN, E.; PAULINO, M.F.; ZERVOUDAKIS, J.T. et al. Suplementação de novilhos mestiços durante a época das águas: parâmetros ingestivos e digestivos. Rev. Bras. Zootec., v.30, p.1340-1349, 2001a.

DETMANN, E.; PAULINO, M.F.; ZERVOUDAKIS, J. T. et al. Cromo e indicadores internos na determinação do consumo de novilhos mestiços, suplementados, a pasto. Rev. Bras. Zootec., v.30, p.1600-1609, 2001b.

DETMANN, E.; PAULINO, M.F.; CECON, P.R. et al. Níveis de proteína em suplementos para terminação de bovinos em pastejo durante o período de transição seca/águas: digestibilidade aparente e parâmetros do metabolismo ruminal e dos compostos nitrogenados. Rev. Bras. Zootec., v.34, p.1380-1391, 2005.

FIGUEIREDO, D.M.; PAULINO, M.F.; MORAES, E.H.B.K. et al. Efeito de diferentes fontes de proteína em suplementos múltiplos para novilhas em pastejo no período das águas: 2- $\mathrm{pH}$ e concentrações de amônia ruminal. In: REUNIÃO ANUAL DA SOCIEDADE BRASILEIRA DE ZOOTECNIA, 41., 2004, Campo Grande. Anais... Campo Grande: SBZ, 2004. (CD-ROM).

HUNTER, R.A. Strategic supplementation for survival, reproduction and growth of cattle. In: GRAZING LIVESTOCK NUTRITION CONFERENCE, 2., 1991, Stemboat Springs. Proceedings... Stemboat Springs:McCollum III F.T. Oklahoma State University, 1991. p.32-47.
ÍTAVO, L.C.V.; VALADARES FILHO, S.C.; SILVA, F.F. et al. Produção microbiana e parâmetros ruminais em novilhos alimentados com dietas contendo vários níveis de concentrado. Rev. Bras. Zootec., v.31, p.1553-1561, 2002.

LAZZARINI, I. Consumo, digestibilidade dinâmicas de trânsito e degração da fibra em detergente neutro em bovinos alimentados com forragem tropical de baixa qualidade e compostos nitrogenados. 2007. 52f. Dissertação (Mestrado em Zootecnia) - Universidade Federal de Viçosa, Viçosa-MG.

LENG, R.A. Factors affecting the utilization of "poor-quality" forages by ruminants particularly under tropical conditions. Nutr. Res. Rev., v.3, p.277-303, 1990 .

McMENIMAN, N.P. Methods of estimating intake of grazing animals. In: REUNIÃO ANUAL DA SOCIEDADE BRASILEIRA DE ZOOTECNIA, 34., 1997, Juiz de Fora. Anais... Juiz de Fora: SBZ, 1997. p.131-168

MINSON, D.J. Forage in ruminant nutrition. San Diego: Academic, 1990. 483p.

MORAES, E.H.B.K. Desempenho e exigências de energia, proteína e minerais de bovinos de corte em pastejo, submetidos a diferentes estratégias de suplementação. 2006. 136f. Tese (Doutorado em Zootecnia) - Universidade Federal de Viçosa, Viçosa-MG.

MOULD. F.L.; ØRSKOV, E.R.; MANN, S.O. Associative effects of mixed feeds. 2. The effect of dietary additions of bicarbonate salts on the voluntary intake and digestibility of diets containing various proportions of hay and barley. Anim. Feed Sci. Technol., v.10, p.25, 1983.

NUTRIENT requirements of dairy cattle. 7.ed. Washington, DC: Academic, 2001. 381p.

PAULINO, M.F.; ZERVOUDAKIS, J.T.; MORAES, E.H.B.K. et al. Bovinocultura de ciclo curto em pastagens. In: SIMPÓSIO DE PRODUÇÃO DE GADO DE CORTE, 3., 2002, Viçosa. Anais... Viçosa, MG: SIMCORTE, 2002a. p.153-196.

PAULINO, M.F.; MORAES, E.H.B.K.; ZERVOUDAKIS, J.T. et al. Suplementação de novilhos mestiços recriados em pastagens de Brachiaria decumbens durante o período das águas: desempenho. In: REUNIÃO ANUAL DA SOCIEDADE BRASILEIRA DE ZOOTECNIA, 39., 2002, Recife. Anais... Recife: SBZ, 2002 b. (CD-ROM, Nutrição de Ruminantes). 
PAULINO, M.F.; MORAES, E.H.B.K. ZERVOUDAKIS, J.T. et al. Terminação de novilhos mestiços leiteiros sob pastejo, no período das águas, recebendo suplementação com soja. Rev. Bras. Zootec., v.35, p.154-158, 2006.

PORTO, M. O. Suplementos múltiplos para recria e terminação de bovinos em pastejo durante o período das águas. 2005. 99f. Dissertação (Mestrado em Zootecnia) - Universidade Federal de Viçosa, Viçosa, MG.

RENNÓ, L.N.; VALADARES FILHO, S.C.; VALADARES, R.F. et al. Estimativas da excreção urinária de derivados de purinas e da produção de proteína microbiana em novilhos alimentados com níveis crescentes de ureia na ração. In: REUNIÃO ANUAL DA SOCIEDADE BRASILEIRA DE ZOOTECNIA, 39., 2002, Recife. Anais... Recife: SBZ, 2002. (CD-ROM, Nutrição de Ruminantes).

SATTER, L.D.; SLYTER, L.L. Effect of ammonia concentration on rumen microbial protein production in vitro. Br. J. Nutr., v.32, p.199-208, 1974.

SILVA, D.J.; QUEIROZ, A.C. Análise de alimentos: métodos químicos e biológicos. 3.ed. Viçosa: UFV, 2002. 165p.

USHIDA, K.; LASSALAS, B.; JOUANY, J.P. Determination of assay parameters for RNA analysis in bacterial and duodenal samples by spectrophotometry. Influence of treatment and preservation. Reprod. Nutr. Dev., v.25, p.10371046, 1985.

VALADARES FILHO, S.C.; MAGALHÃES, K.A.; ROCHA JÚNIOR, V.R. et al. Tabelas Brasileiras de Composição de Alimentos para Bovinos. CQBAL 2.0. 2.ed. Viçosa: UFV, 2006a. 329p.

VALADARES FILHO, S.C.; PAULINO, P.V.R.; DETMANN, E. et al. Exigências nutricionais de zebuínos no Brasil: I. Energia. In: VALADARES FILHO, S.C.; PAULINO, P.V.R.; MAGALHÃES, K.A. Exigências nutricionais de zebuínos e tabelas de composição de alimentos BR-Corte. Viçosa: UFV, 2006b. 142p.
VALADARES， R.F.D.; GONÇALVES， L.C.; RODRIGUEZ. N.M. et al. Níveis de proteína bruta em dietas de bovinos. 4. Concentração de amônia ruminal, ureia plasmática e excreções de creatinina. Rev. Bras. Zootec., v.26, p.1270-1278, 1997.

VILLELA, S.D.J.; PAULINO, M.F.; VALADARES FILHO, S.C. et al. Efeito da suplementação com diferentes fontes de proteína para bovinos de corte em pastejo no período das águas: 1 Desempenho. In: REUNIÃO ANUAL DA SOCIEDADE BRASILEIRA DE ZOOTECNIA, 40., 2003, Santa Maria-RS. Anais... Santa Maria: SBZ, 2003. (CD-ROM, Nutrição de Ruminantes).

VILLELA, S.D.J. Fontes de proteína em suplementos múltiplos para bovinos em pastejo. 2004. 129f. Tese (Doutorado em Zootecnia) Universidade Federal de Viçosa, Viçosa, MG.

WALLACE, R.J.; ONODERA, R.; COTTA, M.A. Metabolism of nitrogen-containing compounds. In: HOBSON, R.J.; STEWART, C.S. (Eds.). The rumen microbial ecosystem. 2.ed. London: Blackie Academic \& Professional, 1997. p.283-328.

ZERVOUDAKIS, J.T.; PAULINO, M.F.; DETMANN, E. et al. Desempenho e características de carcaça de novilhos suplementados no período das águas. Rev. Bras. Zootec., v.34, p.1381-1389, 2001.

ZERVOUDAKIS, J.T. Suplementos múltiplos de autocontrole de consumo e frequência de suplementação, na recria durante os períodos das águas e transição águas-seca. 2003. 78f. Tese (Doutorado em Zootecnia) - Universidade Federal de Viçosa, Viçosa-MG. 